\title{
MODELLING OF RESIDUAL STRESSES, RADIATION SWELLING AND STRESSED STATE OF IN-SERVICE WWER-1000 REACTOR BAFFLE
}

\author{
O.V. MAKHNENKO, I.V. MIRZOV and V.B. POROKHONKO
}

E.O. Paton Electric Welding Institute, NASU

11 Kazimir Malevich Str., 03680, Kiev, Ukraine. E-mail: office@paton.kiev.ua

\begin{abstract}
The question of effect of baffle residual welding stresses on radiation swelling value has appeared in course of works on life extension of WWER-1000 reactor internals at the second power generating unit of the South-Ukrainian NPP. The E.O. Paton Electric Welding Institute has developed and realized a mathematical model for determination of residual stress-strain state of WWER-1000 reactor baffle in electroslag welding with further heat treatment as well as a model for calculation of baffle radiation swelling taking into account radiation creep. It can be stated based on the results of mathematical modelling that the baffle stressed state after 60 years of operation, calculated taking into account residual welding stresses, is close to the results received using the model without welding. This work studies relaxation of residual welding stresses in the WWER-1000 baffle under effect of irradiation and works out their in-service value-to-time dependence. 15 Ref., 3 Tables, 11 Figures.
\end{abstract}

Keywords : WWER-1000, baffle, electroslag welding, residual welding stresses, heat treatment, radiation swelling, radiation creep, mathematical modelling

WWER-1000 reactor internals include the baffle made from $08 \mathrm{Kh} 18 \mathrm{~N} 10 \mathrm{~T}$ steel and subjected to in-service porosity accumulation resulting in irreversible increase of material volume. This effect is termed radiation swelling and can result in significant change of structure stressed state in operation.

According to technical documents for the second power unit of the South-Ukrainian NPP, WWER-1000 reactor baffle of V-338 series was manufactured using electroslag welding (ESW) (Figure 1). The welded joints require consideration of effect of residual welding stresses (RWS) on change of the stress-strain state (SSS) of in-service baffle. Therefore, today it is relevant to study RWS in the baffle taking into account radiation swelling, that is interesting from point of view of design-basis justification of the internals life.

Work [1] experimentally determines insignificant reduction of the RWS in the specimens irradiated with 0.3-1.0 dpa doses at $300{ }^{\circ} \mathrm{C}$ temperature. The same work studies the baffle welded joint irradiated to the level of 20-30 dpa for 60 years taking into account structure service stresses. The similar investigation was carried out in [2] for WWER-1000 core.

The aim of the present work is development of the mathematical model for SSS determination in zone of baffle welded joints taking into account their heat treatment, calculation of baffle radiation swelling considering RWS and analysis of stressed state of
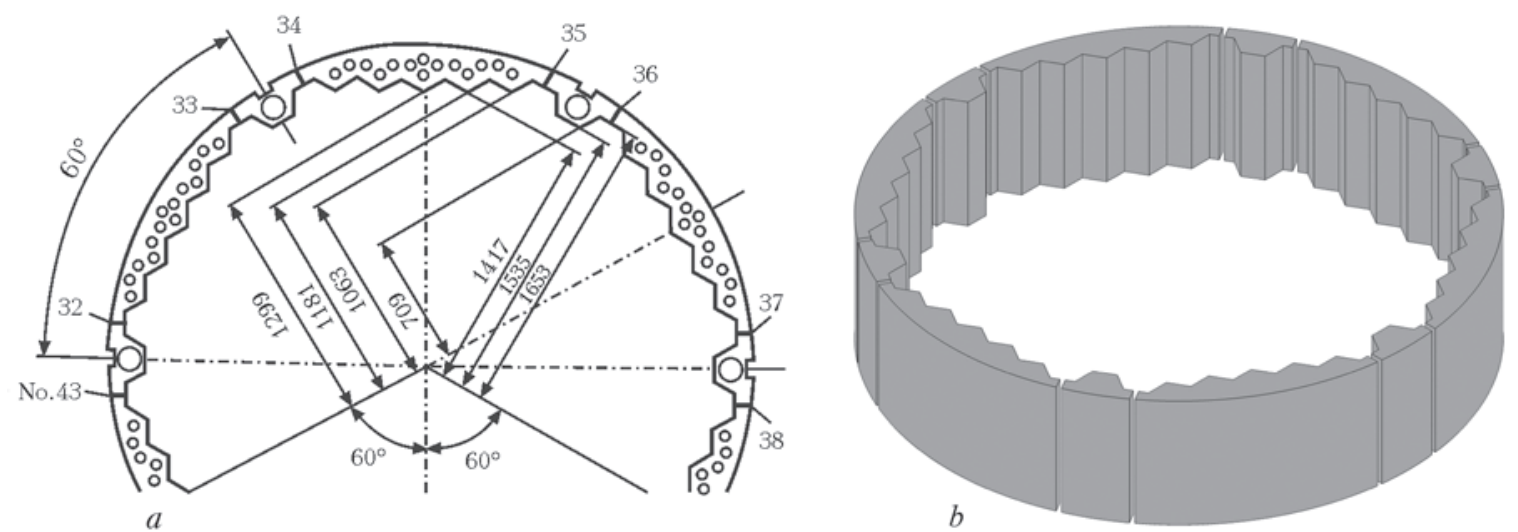

Figure 1. Baffle central ring: $a$ - drawing of section from part passport with location of welds Nos $32-38-43$; $b-$ segments of baffle ring before ESW 
Table 1. Main parameters of consumable-nozzle ESW of WWER1000 baffle

\begin{tabular}{|l|c|}
\hline \multicolumn{1}{|c|}{ Parameter } & Value \\
\hline Welding current $I_{\mathrm{a}}, \mathrm{A}$ & 600 \\
\hline Voltage $U_{\mathrm{w}}, \mathrm{V}$ & 46 \\
\hline Electrode feed rate $v_{\mathrm{e} . \mathrm{f}}, \mathrm{m} / \mathrm{h}$ & 230 \\
\hline Welding speed $v_{\mathrm{w}}, \mathrm{mm} / \mathrm{s}$ & 0.42 \\
\hline Depth of liquid metal pool, mm & 40 \\
\hline Temperature of liquid metal pool $T_{\max },{ }^{\circ} \mathrm{C}$ & 2000 \\
\hline Nozzle thickness, mm & 10 \\
\hline Wire diameter, mm & 3 \\
\hline $\begin{array}{l}\text { Amount of main/reserved electrode wires, } \\
\text { pcs }\end{array}$ & $2 / 2$ \\
\hline Flux & 48 -OF-6 \\
\hline Electrode wire grade [7] & Sv-04Kh19N11M3 \\
\hline Heat efficiency of process $\eta$ & 0.85 \\
\hline
\end{tabular}

baffle welded joints after irradiation in course of 60 years of operation.

Baffle welding using electroslag technology. Baffle rings are welded from forged segments with the help of ESW [3-5]. Appearance of baffle ring welded elements is shown in Figure $1, b$. Thickness of the metal in place of welding makes $76-79 \mathrm{~mm}$ (Figure 2), weld length is $814 \mathrm{~mm}$.

The special documents [4] state that ESW schemes using wire electrode and consumable nozzle (Figure 3) are mainly used for assemblies and structures of NPP of 70-100 mm thickness.

As applicable to baffle ring manufacture, the safest from process point of view and the most relevant from point of view of welded joint quality is consumable nozzle ESW scheme (Figure 3, $b$ ). Welding is carried out per one pass on special stands with rigid fixation of welded part.

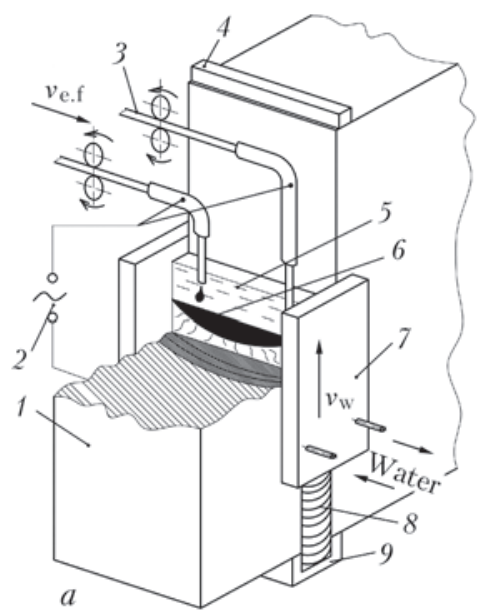

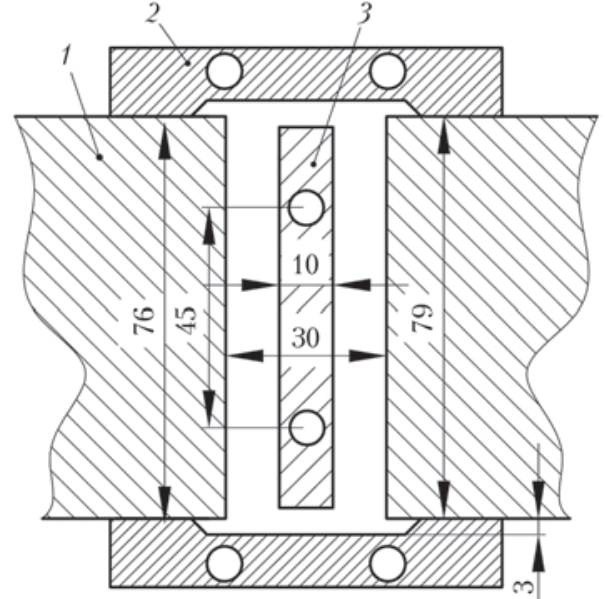

Figure 2. Parameters of part assembly for ESW: 1 - parts to be welded; 2 - water-cooled forming plate (mold); 3 - nozzle

The welding gap is set taking into account shrinkage deformations. It makes $28 \mathrm{~mm}$ in the joint lower part and $30 \mathrm{~mm}$ is the upper one [6]. The consumable nozzle is made from the same steel grade that in the base metal. The nozzle includes the channels for main and reserved wires (Sv-04Kh19N11M3 wire is used) [7]. The technology provides for a starting block and run-on plates which are mechanically removed after welding. The main parameters of baffle ESW with consumable nozzle are given in Table 1. Welding power source can be evaluated: $P=I U \eta=$ $=600 \cdot 46 \cdot 0.85 \approx 23 \mathrm{~kW}$.

ESW joints are subjected to heat treatment on modes determined for the base metal.

Development of mathematical models. The E.O. Paton Electric Welding Institute developed and realized the mathematical model of baffle ESW with further heat treatment. The results of RWS calculation using this model made a basis for calculations of baffle radiation swelling, made using the model of CRI of Structural Materials «Prometey», St.-Petersburg $[7,8]$. Also data on volumetric heat generation and

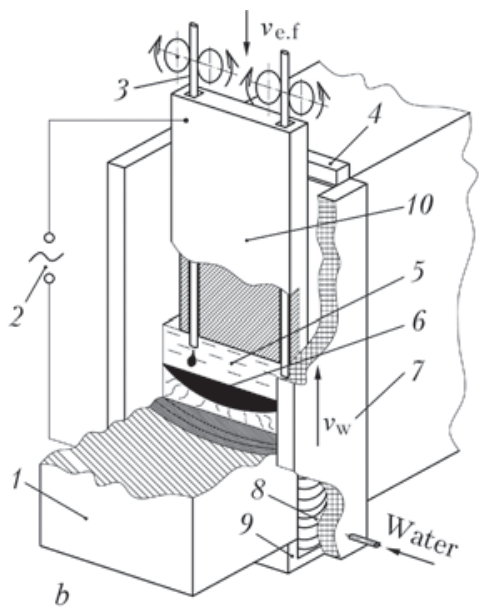

Figure 3. ESW schemes using wire electrodes $(a)$ and consumable nozzle $(b)$ : 1 — parts being welded; 2 - power source; 3 - welding wire; 4 - run-on plate; 5 - slag pool; 6 - metal pool; 7 - water-cooled forming plate (mold); 8 - weld; 9 - starting block; 10 - nozzle 
Table 2. Chemical composition of internals base and weld metal, wt.\%

\begin{tabular}{|c|c|c|c|c|c|c|c|c|c|c|c|}
\hline Material & $\delta$-ferrite & $\mathrm{C}$ & $\mathrm{Cr}$ & $\mathrm{Ni}$ & $\mathrm{Mn}$ & $\mathrm{Si}$ & $\mathrm{Ti}$ & $\mathrm{S}$ & $\mathrm{P}$ & $\mathrm{Mo}$ & $\mathrm{V}$ \\
\hline Base metal & $2-3$ & 0.06 & 17.89 & 9.06 & 1.17 & 0.31 & 0.6 & 0.010 & 0.009 & & \\
\hline Weld metal & 4.4 & 0.07 & 17.50 & 10.33 & 2.40 & 0.22 & & 0.006 & 0.025 & 2.36 & 0.62 \\
\hline
\end{tabular}

damaging dose rate in the baffle, obtained at Institute for Nuclear Research of the NAS of Ukraine [9] and DB «Gidropress», Podolsk, RF [10] were used in calculations.

Modelling of ESW. Baffle material is austenite steel 08Kh18N10T. Chemical composition of steel and internals welded assemblies in the initial (non-irradiated) state is taken from $[7,11]$ and given in Table 2.

As can be seen from Table 2, chemical composition of the welded joint has insignificant difference from that of the base metal, therefore, it is assumed that the baffle is uniform and all its volume has $08 \mathrm{Kh} 18 \mathrm{~N} 10 \mathrm{~T}$ steel properties. Dependence of steel yield strength on temperature taken from different sources is given in Figure 4. 3D finit-element model of baffle being welded is given in Figure 5.

Thickness of one layer of numerical elements in weld zone makes $h=8.14 \mathrm{~mm}$ and baffle height division contains 100 layers. The ESW modeling problem is referred to a moving boundary problem. Molten metal front edge is moved up on the part. Time $d t$, during which the front edge is shifted to height $h$ of one numerical element, makes

$$
d t=\frac{h}{v}=\frac{8.14}{0.42} \approx 19 \mathrm{~s} .
$$

The speed of ESW $d V / d t$ can be evaluated on volume of metal being melted. Weld pool area makes $S=30 \cdot 77.5=2323 \mathrm{~mm}^{2}$. Volume of the metal melted in $d t$ time equals $d V=S h \approx 18.9 \mathrm{~cm}^{3}$. Then $d V /$ $d t \approx 1 \mathrm{~cm}^{3} / \mathrm{s}$. Amount of energy $d Q$, necessary for heating of $d V=18.9 \mathrm{~cm}^{2}$ of metal from $T_{\min }=20^{\circ} \mathrm{C}$ to $T_{\max }=2000{ }^{\circ} \mathrm{C}$, is also evaluated:

$$
d Q=d m\left(c \Delta T_{1}+L+c \Delta T_{2}\right)
$$

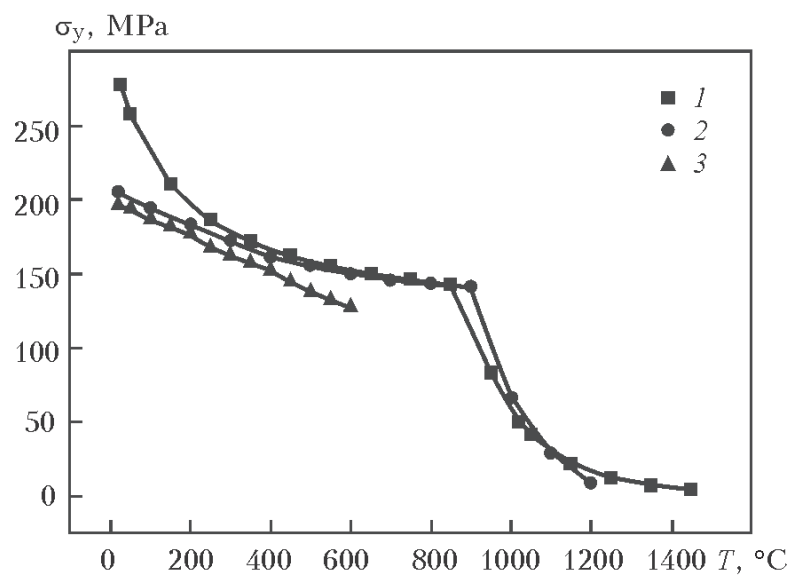

Figure 4. Yield strength of 08Kh18N10T steel versus temperature: 1 - JmatPro program calculation; 2 - Nejmark [12]; 3 PNAE [13] where $c$ is the specific mass heat capacity of metal, $\mathrm{J} /$ $(\mathrm{kg} \cdot \mathrm{K}) ; d m$ is the material $d V$ volume mass; $\Delta T_{1}$ is the temperature range from $20^{\circ} \mathrm{C}$ to melting temperature $T_{\text {liq }}=1450{ }^{\circ} \mathrm{C} ; L$ is the specific mass melting heat, $\mathrm{J} /$ $\mathrm{kg} ; \Delta T_{2}$ is the temperature range from $T_{\text {liq }}$ to $T_{\max }$.

It is more convenient to transfer to volumetric heat capacity and meting heat:

$$
\begin{aligned}
d Q & =d V\left(c \rho \Delta T_{1}+L \rho+c \rho \Delta T_{2}\right)= \\
& =d V\left(c_{\rho} \Delta T_{1}+L_{\rho}+c_{\rho} \Delta T_{2},\right.
\end{aligned}
$$

where $\rho$ is the average density of steel in the whole temperature range; $c_{\rho}=c \rho$ is the specific volumetric heat capacity of metal, $\mathrm{J} /\left(\mathrm{m}^{3 \cdot} \mathrm{K}\right) ; L_{\rho}=L \rho$ is the specific volumetric melting heat, $\mathrm{J} / \mathrm{m}^{3}$.

$$
\begin{aligned}
& \begin{array}{l}
\text { At } T \in\left[T_{\text {min }} ; T_{\text {liq }}\right] \bar{\rho}=7575 \mathrm{~kg} / \mathrm{m}^{3} . \\
\text { Then }
\end{array} \\
& \begin{aligned}
c= & 462 \mathrm{~J} /(\mathrm{kg} \cdot \mathrm{K}) \rightarrow c_{\rho}=462 \cdot 7575= \\
= & 3.5 \cdot 10^{6} \mathrm{~J} /\left(\mathrm{m}^{3} \cdot \mathrm{K}\right)=3.5 \mathrm{~J} /\left(\mathrm{cm}^{3} \cdot \mathrm{K}\right) ; \\
L= & 277 \mathrm{~kJ} / \mathrm{kg} \rightarrow L_{\rho}=277 \cdot 10^{3} \cdot 7575= \\
& =2.1 \cdot 10^{9} \mathrm{~J} / \mathrm{m}^{3}=2100 \mathrm{~J} / \mathrm{cm}^{3} ; \\
d Q & =3.5 \cdot 18.9(1450-20)+2100 \cdot 18.9+ \\
& +3.5 \cdot 18.9(200-1450) \approx 171 \mathrm{~kJ} .
\end{aligned}
\end{aligned}
$$

Power consumed in welding makes $P=d Q / d t=$ $=171 / 19=9 \mathrm{~kW}$.

Given evaluations show that parameters of ESW mode provide sufficient power for baffle heating (60\%) and weld metal melting (40\%).

Time increment $\tau$ for solving temperature problem is determined from relationship

$$
\tau<\frac{c_{\rho} h^{2}}{2 \lambda},
$$

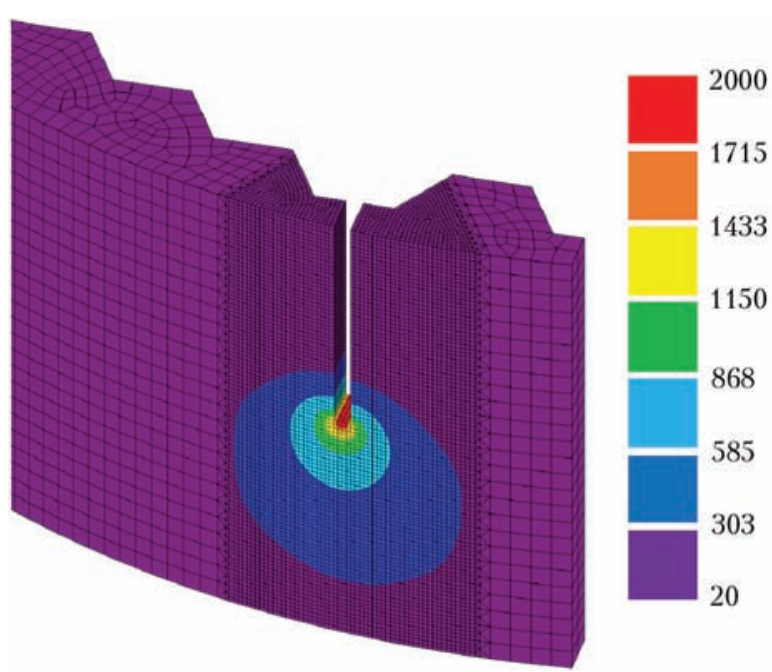

Figure 5. Numerical mesh, temperature $\left({ }^{\circ} \mathrm{C}\right)$ and penetration zone in 3D model of ESW 
where $h=0.814 \mathrm{~cm}$ is the thickness of numerical element (discrete layer of molten metal for time $d t$ ); $\lambda=$ $\lambda(T)$ is the heat conduction; $\left.\lambda\right|_{T=20}=1.6 \mathrm{~W} /(\mathrm{m} \cdot \mathrm{K})=$ $=0.166 \mathrm{~W} /(\mathrm{cm} \cdot \mathrm{K}) ;\left.\lambda\right|_{T=1000}=30 \mathrm{~W} /(\mathrm{m} \cdot \mathrm{K})=0.3 \mathrm{~W} /$ $(\mathrm{cm} \cdot \mathrm{K})$;

$$
\left.\tau\right|_{T=20}>\left.\tau\right|_{T=1000}<\frac{3.5 \cdot 0.814^{2}}{2 \cdot 0.3} \approx 3.9 \mathrm{~s} .
$$

Thus, time step $d t$ should be divided for $[d t / \tau]=5$ increments or more for convergence of temperature problem solution. The increment can exceed $\tau$ for mechanical problem.

Heat treatment modelling. Critical welded structures of the elements of NPP equipment are subjected to mandatory heat treatment, which allows reducing the level of RWS. Thus, WWER-1000 baffle after welding is subjected to heat treatment on high-temperature tempering mode at $650{ }^{\circ} \mathrm{C}$. Rise of temperature reduces the material yield strength, and RWS are relaxed due to instantaneous plasticity effect. Effect of material creep, which takes place at indicated temperature, has even more influence on RWS relaxation.

Creep strain rate $\dot{\varepsilon}_{\mathrm{eq}}^{\mathrm{cr}}=A \sigma_{\mathrm{eq}}^{n}$ is related with the stress intensity $\sigma_{\text {eq }}$ by Norton law [14]. Therefore, gain of creep strain intensity makes $d \varepsilon_{\mathrm{eq}}^{\mathrm{cr}}=A \sigma^{n} d t$ for $d t$ time increment.

For baffle material at $T=650{ }^{\circ} \mathrm{C}$ the creep function $\dot{\varepsilon}_{\text {eq }}^{\text {cr }}(\sigma)$ looks like

$$
d \varepsilon_{\mathrm{eq}}^{\mathrm{cr}}=6.07307 \cdot 10^{-14} \sigma^{4.8351} d t .
$$

Dependence (4) is shown in Figure 6.

Radiation swelling model. Dependence of radiation swelling $d \varepsilon_{\mathrm{eq}}^{\mathrm{sw}}$ on damaging dose $D$ have power nature $[8,15]$ :

$$
\begin{aligned}
& \frac{d \varepsilon_{\mathrm{eq}}^{\mathrm{sw}}}{d t}=C_{D} n D(t)^{n-1} f_{1}(T) f_{2}\left(\sigma_{\mathrm{m}}, \sigma_{\mathrm{eq}}\right) f_{3}(æ) \frac{d D}{d t} ; \\
& d \varepsilon_{\mathrm{eq}}^{\mathrm{sw}}>0 ;\left.d \varepsilon_{\mathrm{eq}}^{\mathrm{sw}}\right|_{t=0}=0 \text {; } \\
& f_{1}(T)=\exp \left(-r\left(T-T_{\max }\right)^{2}\right) ; \\
& f_{2}\left(\sigma_{\mathrm{m}}, \sigma_{\mathrm{eq}}\right)=1+8 \cdot 10^{-3}\left(0.85 \sigma_{\mathrm{m}}+0.15 \sigma_{\mathrm{eq}}\right) \text {; }
\end{aligned}
$$

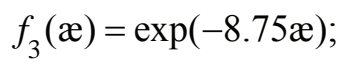

$$
\begin{aligned}
& C_{D}=1.035 \cdot 10^{-4} ; n=1.88 \text {; } \\
& r=1.825 \cdot 10^{-4} ; T_{\max }=470{ }^{\circ} \mathrm{C} \text {; } \\
& \sigma_{\mathrm{m}}=\frac{\sigma_{x x}+\sigma_{y y}+\sigma_{z z}}{3},
\end{aligned}
$$

where $\sigma_{x x}, \sigma_{y y}, \sigma_{z z}$ are the normal components of stress tensor;

$$
æ=\int_{0}^{D} d \varepsilon_{\mathrm{i}}^{\mathrm{p}},
$$

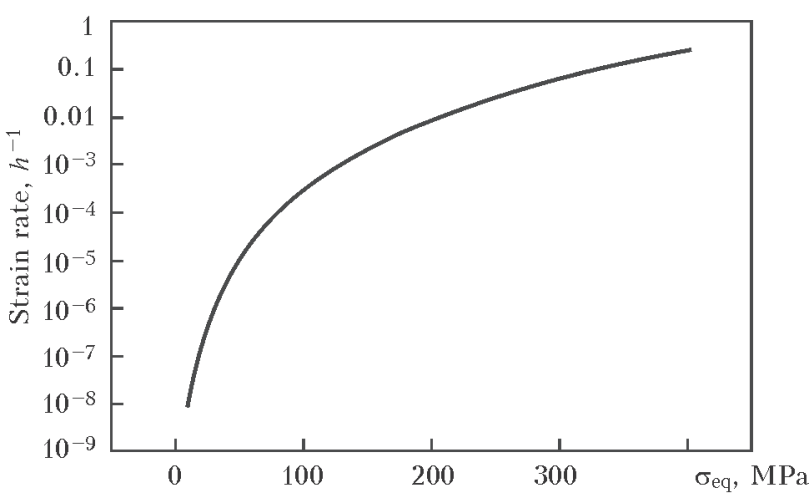

Figure 6. Creep function for steel $08 \mathrm{Kh} 18 \mathrm{~N} 10 \mathrm{~T}$ at $T=650{ }^{\circ} \mathrm{C}$

where $d \varepsilon_{\mathrm{i}}^{\mathrm{p}}=\frac{\sqrt{3}}{2} \sqrt{d \varepsilon_{i j}^{\mathrm{p}} d \varepsilon_{i j}^{\mathrm{p}}}, i, j=1,2,3$ is the intensity of plastic strain gain.

In order to consider radiation creep the expression is supplemented with relationship

$$
\begin{aligned}
& \frac{d \varepsilon_{\mathrm{eq}}^{\mathrm{cr}}}{d t}=\left(B_{0} \frac{d D}{d t}+\omega \frac{d \varepsilon_{\mathrm{eq}}^{\mathrm{sw}}}{d t}\right) \sigma_{\mathrm{eq}} ; \\
& d \varepsilon_{\mathrm{eq}}^{\mathrm{cr}}>0 ;\left.\varepsilon_{\mathrm{eq}}^{\mathrm{cr}}\right|_{t=0}=0 ; \\
& B_{0}=1 \cdot 10^{-6}(\mathrm{MPa} \cdot \mathrm{dpa})^{-1} ; \\
& \omega=2.95 \cdot 10^{-3} \mathrm{MPa}^{-1} .
\end{aligned}
$$

A total tensor of swelling strain gain $d \varepsilon$ is present as a sum of gain of radiation creep strain $d \varepsilon_{\mathrm{eq}}^{\mathrm{cr}}$ (deviator component) and gain of radiation swelling $d \varepsilon_{\mathrm{eq}}^{\mathrm{sw}}$ (spherical component) in this time step:

$$
d \varepsilon=\frac{1}{3} d \varepsilon_{\mathrm{eq}}^{\mathrm{sw}} \mathbf{I}+d \varepsilon_{\mathrm{eq}}^{\mathrm{cr}} \mathbf{n},
$$

where $\mathbf{I}$ is the identity tensor; $\mathbf{n}=d \sigma_{\mathrm{eq}} / d \sigma$ is the stress intensity; $\sigma$ is the stress tensor.

Strain gains $d \varepsilon$ are summed in all time steps, $\varepsilon$ is the total tensor of radiation swelling strain, and its first variant is taken for volumetric swelling strain.

The relationships taken from [7] allows considering the change of material yield strength depending on radiation dose as well as temperature (see Figure 4) in the radiation swelling problem:

$$
\begin{gathered}
\sigma_{0.2}(T, D)=\left\{\begin{array}{c}
\sigma_{0.2}^{0}(T)+\Delta \sigma_{0.2}^{T}(T, D), \quad D<D^{*}, \\
\sigma_{0.2}^{*}(T)+\Delta \sigma_{0.2}^{*}(D), \quad D \geq D^{*} ;
\end{array}\right. \\
\sigma_{0.2}^{0}(T)=155+239 \exp \left(-2.22 \cdot 10^{-3}(T+273)\right), \mathrm{MPa} ; \\
\Delta \sigma_{0.2}^{T}(T, D)=\left(\sigma_{0.2}^{*}(T)-\sigma_{0.2}^{0}(T)\right) \frac{\sqrt{1-\exp \left(-C_{\sigma_{0.2}} D\right)}}{\sqrt{1-\exp \left(-C_{\sigma_{0.2}} D^{*}\right)}} \\
\sigma_{0.2}^{*}(T)=650+1405 \exp \left(-5.9 \cdot 10^{-3}(T+273)\right), \mathrm{MPa} ; \\
\Delta \sigma_{0.2}^{*}(D)=A_{\sigma_{0.2}}\left(\sqrt{1-\exp \left(-C_{\sigma_{0.2}} D\right)}-\sqrt{1-\exp \left(-C_{\sigma_{0.2}} D^{*}\right)}\right) ; \\
D^{*}=7 \mathrm{dpa}, C_{\sigma_{0.2}}=0.126 \mathrm{dpa}^{-1}, A_{\sigma_{0.2}}=621 \mathrm{MPa} .
\end{gathered}
$$


Table 3. Maximum compressive/tension RWS in baffle, MPa

\begin{tabular}{|l|c|c|c|}
\hline \multicolumn{1}{|c|}{ Stage } & Radial & Circumferential & Axial (longitudinal) \\
\hline 1. After welding & $-64 / 90$ & $-52 / 105$ & $-109 / 304$ \\
\hline 2 Heat treatment - heating & $-41 / 57$ & $-41 / 75$ & $-67 / 170$ \\
\hline 3. Heat treatment - hot state after tempering & $-23 / 24$ & $-21 / 29$ & $-27 / 50$ \\
\hline 4. Cold state after heat treatment & $-30 / 31$ & $-27 / 37$ & $-34 / 65$ \\
\hline
\end{tabular}

Results. A field of RWS was received in baffle ESW taking into account heat treatment.

The problem of baffle radiation swelling was solved for two cases, i.e. taking into account RWS effect and without it.

All the problems are nonlinear and were solved using tracing on time with the help of finite-element method. The problem of RWS evaluation was solved in $3 \mathrm{D}$ problem statement, all the rest were made in $2 \mathrm{D}$ under the condition of generalized plain strain. The 2D problems consider median section of baffle ring.
Residual welding stresses. Table 3 shows the change of maximum tensile and compressive stresses after welding and in process of heat treatment. The maximum stresses after welding/heat treatment are axial (longitudinal) and their distribution is shown in Figure 7.

The RWS field is laid in the radiation swelling calculation as an initial condition. Model (5) takes into account the effect of stresses on swelling value, therefore, the differences in the swelling fields with and without welding are predicted.

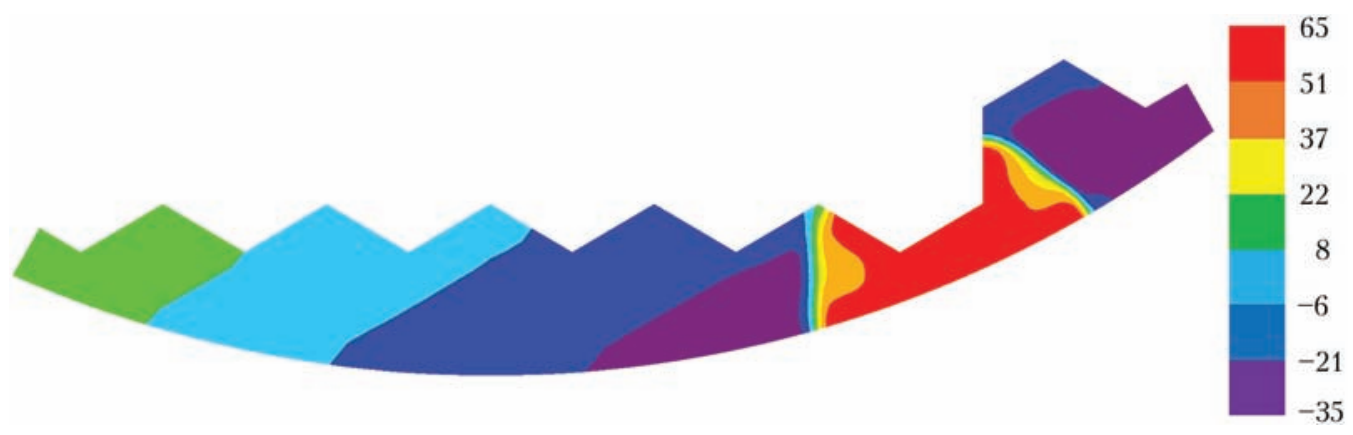

Figure 7. Distribution of axial (longitudinal) RWS in baffle after heat treatment
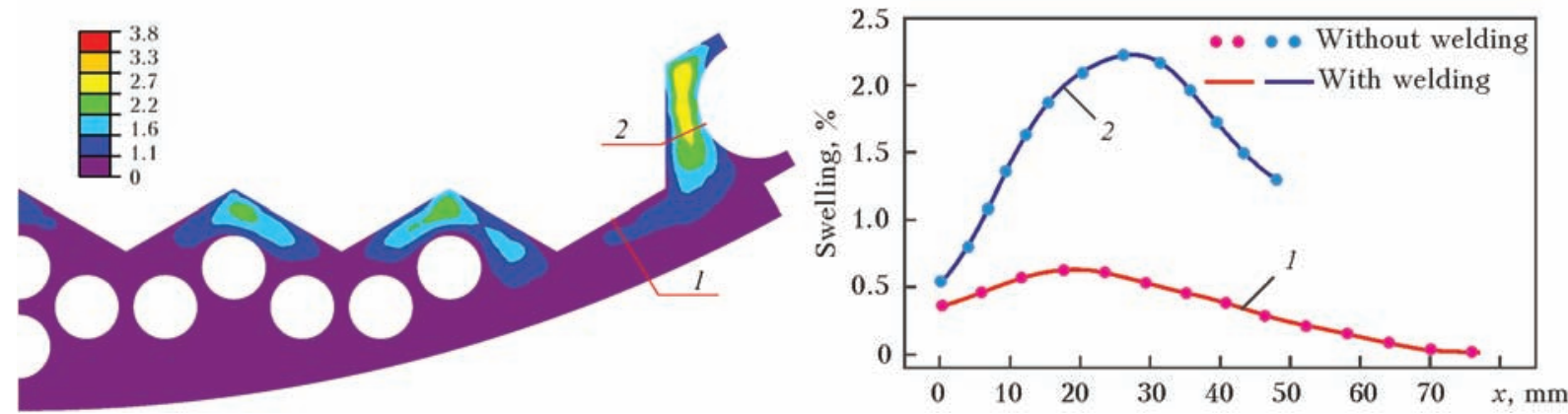

Figure 8. Field of volumetric swelling strain in baffle after 60 years of operation, and distribution of swelling in sections 1 and 2 in the problems with and without RWS
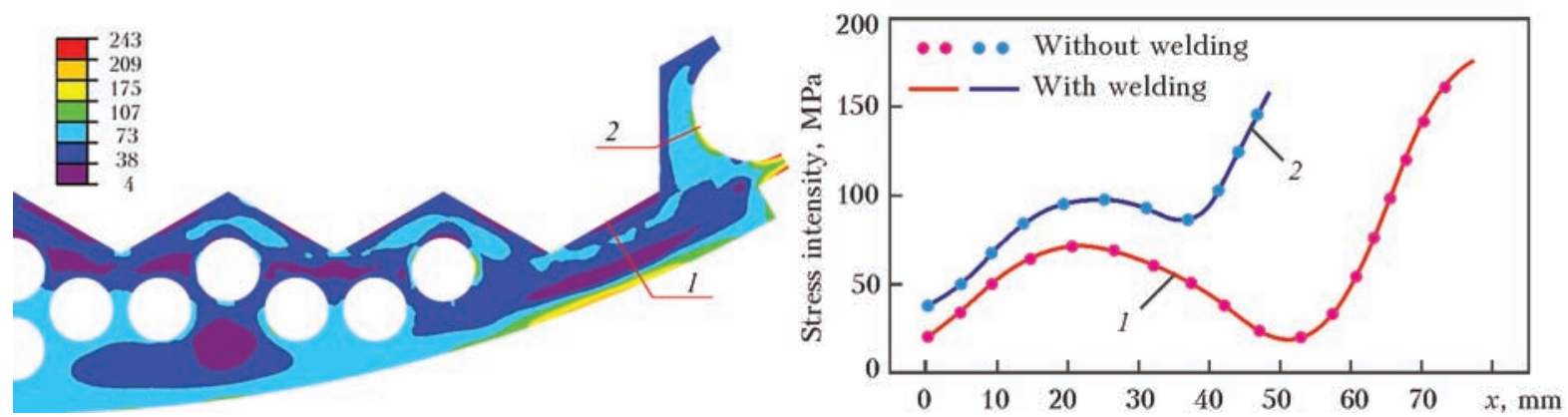

Figure 9. Field of stress intensity in baffle after 60 years of operation, and distribution of stresses in sections 1 and 2 in the problems with and without RWS 

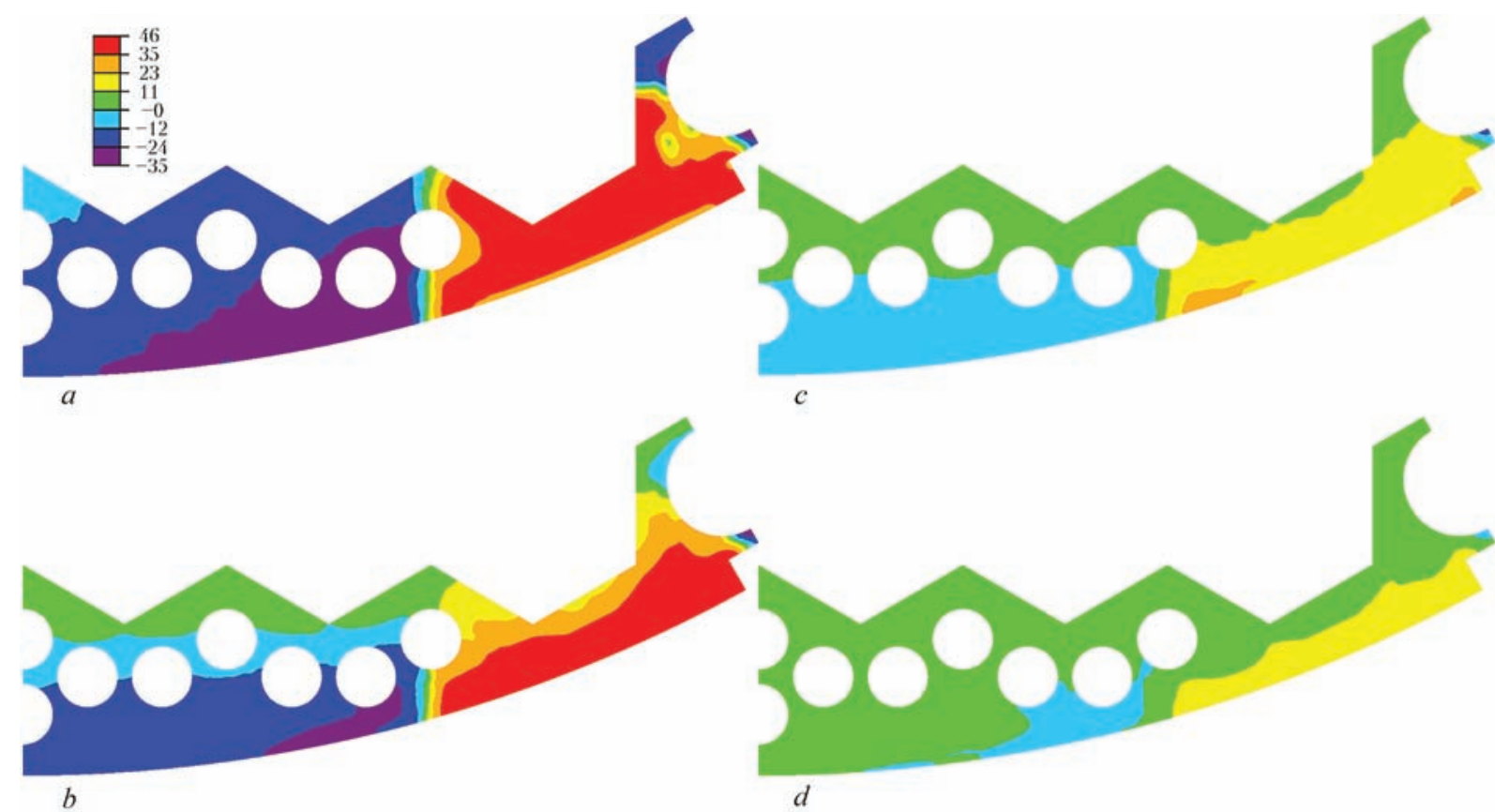

Figure 10. Relaxation of RWS in WWER-1000 baffle: $a$ - in the beginning of operation; $b$ - after 20; $c$ - after 40 ; $d$ - after 60 years of operation

Effect of RWS on in-service swelling and SSS. Figure 8 shows the results of calculation of baffle swelling on models (5)-(8).

The results of calculation of stressed state on models (5)-(8) are shown in Figure 9.

Discussion. The maximum RWS are axial one and in section 1 have sign «+», i.e. being tensile. Tensile stresses according to the model promote growth of radiation swelling. However, the results in Figure 8 do not indicate significant effect of RWS on radiation swelling. In other words, RWS at $65 \mathrm{MPa}$ level are not large enough for influencing the value of swelling in zone of baffle welds.

Besides, as can be seen from Figure 9, $a$, difference of stress distribution in section 1 after 60 years of operation makes around $6 \mathrm{MPa}$, that is significantly lower than RWS level laid in swelling calculation. Such RWS behavior is explained by the effect of radiation creep, laid in the swelling model depending on (6). However, it is essential to find out the way of RWS relaxation under the effect of irradiation. For this, the difference of axial stress fields in the baffle was calculated in different moments of time after operation start. Such an approach allows tracing the history of change of RWS contribution in the total stressed state.

Figure 10 shows reduction of RWS in the baffle on time and explains the results, demonstrated in Figure 9: the stress fields in the baffle after 60 years of operation differ by about $6 \mathrm{MPa}$ in swelling problems with and without welding.

It should be noted that RWS relaxation in the baffle does not happen immediately, it takes place in course

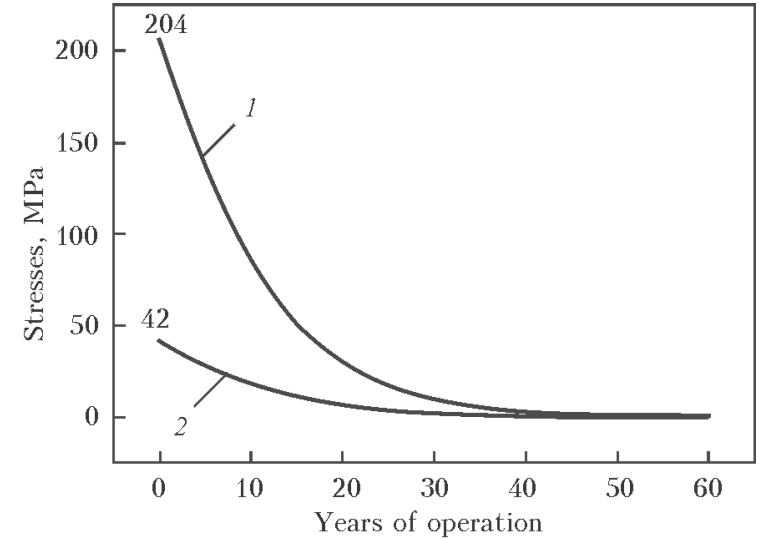

Figure 11. Quantitative characteristic of RSW relaxation in the WWER-1000 baffle in service: 1 - without heat treatment; 2 after heat treatment

of 60 years of reactor operation. Qualitatively this effect can be described using the dependence

$$
\sigma=\sigma_{0} 0.92^{t} \text {, }
$$

where $\sigma_{0}$ is the RWS initial level in the baffle during reactor warming up for normal operation; $t$ is the year of reactor operation.

Dependence (9) is the relationship which can be used for evaluation of static and cyclic strength as well as for evaluation of brittle fracture resistance of baffle material. This relationship is shown in Figure 11.

It should be noted that relationship (9) is received for specific output data such as volumetric heat generation and radiation dose $[9,10]$ which may significantly vary for different power units. Therefore, it is recommended to consider the welded joints in further evaluations on extension of life of WWER-1000 internals. 


\section{Conclusions}

1. The work shows that RWS in WWER-1000 baffle taking into account heat treatment have virtually complete relaxation under effect of irradiation for the period of around 60 years.

2. The history of RWS effect in course of 60 years does not provoke significant change in baffle swelling in zone of welds.

3. The relationship has been deducted for evaluation of baffle RWS value during operation.

4. It is recommended to take into account welded joints in further evaluations of residual life of WWER-1000 internals.

1. (2000) Irradiation effects on the evolution of the microstructure, properties and residual stresses in the heat affected zone of stainless steel welds: INTERWELD Project. FIKSCT-2000-00103.

2. Makhnenko, O.V., Velikoivanenko, E.A., Mirzov, I.V. (2014) Redistribution of residual welding stresses in in-vessel core barrel of WWER-1000 reactor during operation. The Paton Welding J., 11, 8-14.

3. (1980) Electroslag welding and surfacing. Ed. by B.E. Paton. Moscow: Mashinostroenie.

4. (1975) Main principles on welding and surfacing of assemblies and structures of nuclear power plants, pilot and research nuclear reactors and units. Moscow: Metallurgiya.

5. Lychko, I.I., Sushchuk-Slyusarenko, I.I., Yushchenko, K.A. (1999) Specifics of electroslag welding of thick-wall long butts of 18-8 type steel. Avtomatich. Svarka, 9, 61-65.
6. GOST 30482-97: Electroslag welding of steels. Requirements to technological process. Interstate Standard.

7. Sorokin, A.A., Margolin, B.Z., Kursevich, I.P. et al. (2011) Influence of neutron radiation on mechanical properties of internals materials of WWER type reactors. Voprosy Materialovenediya, 66(2), 131-151.

8. Margolin, B.Z., Murashova, A.I., Neustroev, V.S. (2012) Analysis of influence of stressed state type on radiation swelling and radiation creep of austenitic steels. Problemy Prochnosti, 3, 5-24.

9. Pishtora, V., Vandlik, S., Lauerova, D. et al. (2011) Secondary operations on evaluation of technical state of reactor elements of power unit 1 of Yuzhno-Ukrainskaya NPP (Phase 1): Report of IYaI.

10. Margolin, B., Fedorova, V., Sorokin, A. et al. (2012) The mechanisms of material degradation under neutron irradiation for WWER internals and methods for structural integrity assessment. In: Proc. of Int. Conf. on Structural Integrity and Life of NPP Equipment (1-5 Oct. 2012, Kiev, Ukraine).

11. Margolin, B.Z., Kursevich, I.P., Sorokin, A.A. et al. (2009) To problem of radiation swelling and radiation embrittlement of austenitic steels. Pt 2: Physical and mechanical principles of embrittlement. Voprosy Materialovedeniya, 58(2), 99-111.

12. Nejmark, B.E. (1967) Physical properties of steels and alloys used in heat-power engineering: Refer. Book. Moscow; Leningrad: Energiya.

13. PNAE G-7002-86: Codes of design on strength of equipment and pipelines of nuclear power units. Moscow: Energoatomizdat.

14. Rabotnov, Yu.N. (1966) Creep of structure elements. Moscow: GIFML.

15. Margolin, B.Z., Murashova, A.I., Neustroev, V.S. (2011) Effect of stresses on radiation swelling of austenitic steels. Voprosy Materialovedeniya, 68(4), 124-139.

Received 16.02.2015 